\title{
Strategi Pengendalian Alih Fungsi Lahan Pertanian di Subak Kerdung, Kelurahan Pedungan, Kecamatan Denpasar Selatan, Kota Denpasar
}

\author{
LATIEF IKHSAN, I WAYAN WINDIA, \\ NI WAYAN SRI ASTITI
}

\author{
Program Studi Agribisnis, Fakultas Pertanian, Universitas Udayana \\ Jl. PB. Sudirman Denpasar 80232 Denpasar, Bali \\ Email: latiefikhsan10@gmail.com \\ wayanwindia@ymail.com
}

\section{Abstract \\ Strategy for Controlling the Transfer of Agricultural Land Functions in SubakKerdung, Sub-District of South Denpasar, Denpasar City}

Control over the conversion of agricultural land is very necessary in order to maintain the existence and sustainability of subak in the City of Denpasar, especially in SubakKerdung. There needs to be appropriate strategies as a solution so that control over the conversion of agricultural land in SubakKerdung can be done. The purpose of this study was to determine internal and external factors and to find out the most appropriate strategy in controlling the conversion of agricultural land in SubakKerdung. The results of the analysis of internal factors in SubakKerdung were: a) strength (the application of Tri Hita Karana in subak), b) weakness (low interest of subak members to defend their land). External factors were: a) opportunities (the development of ecotourism as a tourist attraction), b) threats (over the function of agricultural land).Based on the SWOT analysis, the development strategies found were: (a) S-O Strategy - Optimizing the empowerment of farmer communities as the main actors in ecotourism development by directly selling their agricultural products to tourists. (b) WO Strategy - Conducting education and training through counseling in adopting new innovations so that agricultural products can be marketed to tourists. (c) S-T Strategy Planting vegetables that have high economic value and can be processed into snacks and drinks (d) The W-T Strategy -Implementing and increasing the intensity of education and training on tour guides, i.e. English training for young people and farming communities.

Keywords: strategy, transfer of agricultural land function, Subak Kerdung, SWOT analysis

\section{Pendahuluan}

\subsection{Latar Belakang}

Beberapa tahun belakangan ini, Bali menghadapi masalah kependudukan. Banyak penduduk dari luar yang datang ke Bali dengan beranekaragam tujuan. Sehinggajumlah pendatang yang masuk ke Bali terus meningkat dan mengakibatkan pertumbuhan penduduk semakin bertambah. Menurut data Badan Pusat Statistik (BPS) Provinsi Bali 
kepadatan penduduk dalam kurun waktu 2012-2015 semakin meningkat. Pada tahun 2012 kepadatan penduduk terhitung sebesar 710,9 jiwa/ km², tahun 2013 sebesar 719,6 jiwa/ km2, tahun 2014 sebesar 728,3 jiwa/ km2, dan tahun 2015 sebesar 736,7 jiwa/ $\mathrm{km}^{2}$. Pesatnya peningkatan kepadatan penduduk di Bali berdampak pada beberapa sektor, salah satunya yaitu sektor pertanian. Ribuan hektar lahan pertanian sekarang sudah beralih fungsi, ada yang menjadi pemukiman, pusat perbelanjaan, pusat industri dan masih banyak lagi.Data dari Badan Pusat Statistik (BPS) Provinsi Bali di tahun Tahun 2014 terjadi alih fungsi lahan pertanian di Bali yang cukup besar yaitu $460 \mathrm{Ha}$ atau 0,77 persen.Peningkatan yang cukup besar di tahun 2014 dikarenakan faktor bertambahnya pemukiman baru. Data dari BPS Provinsi Bali 2011-2015mencatat total luas lahan pertanian yang beralih fungsi dari tahun 2011 sampai 2015 sebesar 1.681 Ha.Terjadinya alih fungsi lahan pertanian yang berkesinambungan dapat mengancam keberlanjutan lahan pertanian dan keberadaan subak yang ada di Bali.

Menurut Utomo, dkk (1992) mendefinisikan alih fungsi lahan sebagai perubahan fungsi sebagian atau seluruh kawasan lahan dari fungsinya semula seperti yang direncanakan menjadi fungsi lain yang berdampak negatif terhadap lingkungan dan potensi lahan itu sendiri.Subak Kerdung yang berlokasi di Kelurahan Pedungan, Kecamatan Denpasar Selatan, Kota Denpasar merupakan salah satu subak yang mengalami alih fungsi lahan pertanian. Subak Kerdung merupakan subak yang memiliki lahan yang paling luas dibandingkan subak-subak lainnya yang ada di Kota Denpasar. Subak Kerdung di tahun 2000 memiliki luas lahan 240 ha dan saat ini pada tahun 2017 luas lahan Subak Kerdung adalah 210 ha, dalam 17 tahun terakhir Subak Kerdung sudah mengalami alih fungsi lahan seluas 30 ha dari lahan pertanian ke non pertanian.

Banyak faktor yang menyebabkan terjadinya alih fungsi lahan, salah satunya karena desakan ekonomi. Pemilik lahan harus menjual lahannya karena kebutuhan ekonomi yang terus bertambah sedangkan produktivitas lahan pertanian yang terus menurun. Peningkatan jumlah penduduk dan perkembangan sektor pariwisata di Kota Denpasar yang sangat pesat membuat pemerintah Kota Denpasar membuat kebijakan tentang alih fungsi lahan pertanian khususnya di Subak Kerdung. Kebijakan tersebut yaitu kawasan jalur hijau tidak diperbolehkan membangun pemukiman atau digunakan untuk keperluan non pertanian, tetapi menurut pekaseh Subak Kerdung (Wayan Tama), kebijakan tersebut tidak sepenuhnya dijalankan. Ada upaya lain yang dilakukan pada tanggal 16 juli 2016 oleh Pemerintah Kota Denpasar melalui Badan Lingkungan Hidup dalam mengendalikan alih fungsi lahan di Kota Denpasar khususnya di Subak Kerdung yaitu Subak Kerdung dikembangkan menjadi kawasan ekowisata, salah satu alasan dipilihnya Subak Kerdung menjadi ekowisata yaitu dari sekian subak yang ada di Denpasar, Subak Kerdung memiliki lahan yang paling luas dibandingkan dengan subak yang ada di Kota Denpasar lainnya.

Pengendalian alih fungsi lahan pertanian sangat diperlukan demi menjaga eksistensi dan kelestarian subak di Kota Denpasar khususnya di Subak Kerdung. Maka perlu adanya strategi-strategi yang tepat sebagai solusi agar pengendalian alih fungsi lahan pertanian di Subak Kerdung bisa ditekan. Sehubungan dengan hal tersebut maka penelitian ini sangat relevan dilakukan di Subak Kerdung, Kelurahan Pedungan, Kecamatan Denpasar Selatan, Kota Denpasar sebagai upaya untuk membuat kebijakan pengendalian alih fungsi lahan pertanian. 


\subsection{Rumusan Masalah}

Berdasarkan latar belakang maka dapat dirumuskan masalah penelitian sebagai berikut.

1. Faktor-faktor apa saja yang menjadi kekuatan, kelemahan, peluang dan ancaman dalam pengendalian alih fungsi lahan pertanian di Subak Kerdung, Kelurahan Pedungan, Kecamatan Denpasar Selatan, Kota Denpasar?

2. Strategi apakah yang paling tepat dalam pengendalian alih fungsi lahan pertanian di Subak Kerdung, Kelurahan Pedungan, Kecamatan Denpasar Selatan, Kota Denpasar?

\subsection{Tujuan}

Berdasarkan latar belakang dan rumusan masalah di atas maka tujuan yang ingin dicapai dalam penelitian ini sebagai berikut.

1. Untuk mengetahui faktor-faktor yang menjadi kekuatan, kelemahan, peluang dan ancaman dalam pengendalian alih fungsi lahan pertanian di Subak Kerdung, Kelurahan Pedungan, Kecamatan Denpasar Selatan, Kota Denpasar.

2. Untuk mengetahui strategi yang paling tepat dalam pengendalian alih fungsi lahan pertanian di Subak Kerdung, Kelurahan Pedungan, Kecamatan Denpasar Selatan, Kota Denpasar.

\section{Metode Penelitian}

\subsection{Lokasi dan Waktu Penelitian}

Penelitian ini dilaksanakan selama lima bulan yaitu bulan Julisampai bulan Oktober 2017 mulai dari persiapan hingga penyusunan laporan. Lokasi penelitian dipilih secara purposive di Subak Kerdung.

\subsection{Jenis dan Sumber Data}

1. Jenis data penelitian ini adalah data kualitatif dan data kuantitatif. Data kualitatif merupakan data yang dinyatakan dalam bentuk kata, kalimat, skema, dan gambar (Sugiyono, 2016). Data kualitatif yang digunakan dalam penelitian ini adalah potensi yang dimiliki Subak Kerdung, nama Pekaseh Subak Kerdung, monografi Subak Kerdung, pendidikan anggota Subak Kerdung dan faktor yang menjadi kekuatan, kelemahan, peluang dan ancaman dalam pengendalian alih fungsi lahan pertanian di Subak Kerdung.Data kuantitatifadalah data yang berupa angka atau dapat dihitung dengan satuan tertentu(Sugiyono, 2016). Data kuantitatif yang digunakan dalam penelitian ini adalah jumlah anggota Subak Kerdung, umur anggota Subak Kerdung dan luas lahan Subak Kerdung.

2. Sumber data penelitian ini adalah data primer dan sekunder. Data primermerupakan data yang didapatkan langsung dari sumber data kepada peneliti(Sugiyono, 2016). Data primer dalam penelitian ini diperoleh melalui wawancara menggunakan daftar pertanyaan (kuesioner) dan wawancara mendalam.Data sekundermerupakan data yang didapatkan secara tidak langsung untuk mendapatkan informasi objek yang diteliti, biasanya data tersebut didapatkan dari pihak kedua baik dari objek secara individual (responden) maupun dari suatu badan (instansi) yang dengan sengaja melakukan pengumpulan data untuk keperluan penelitian (Supangat, 2010). Data sekunder yang 
dikumpulkan antara lain data jumlah petani Subak Kerdung, Awig-Awig Subak Kerdung, monografi Subak Kerdung dan luas lahan Subak Kerdung.

\subsection{Metode Pengumpulan Data}

Data faktor lingkungan internal dan faktor lingkungan eksternal Subak Kerdung, Kelurahan Pedungan, Kecamatan Denpasar Selatan, Kota Denpasardikumpulkan melalui melakukan wawancara langsung dengan responden dengan bantuan daftar pertanyaan (kuesioner) dan wawancara mendalam.

\subsection{Populasi dan Sampel}

Populasi penelitian ini adalah anggota Subak Kerdung berjumlah 200. Sampel (responden) penelitian ini adalah anggota Subak Kerdung yang berjumlah 67. Informan kunci yang juga dijadikan responden yaituPekaseh (Ketua) Subak Kerdung. Pengambilan sampel (responden) penelitian ini dilakukan dengan random sampling.

\subsection{Penentuan Informan Kunci}

Informan kunci dalam penelitian ini untuk pertama kali dipilih secara purposiveyaitu secara sengaja melalui pertimbangan tertentu. Informan kunci tersebut yakni Pekaseh Subak Kerdung Wayan Tama. Pekaseh Subak Kerdung dipilih karena dianggap mengetahui tentang berbagai situasi dan kondisi Subak Kerdung serta seluruh pemangku kepentingan yang terlibat di dalamnya.

\subsection{Instrumen Penelitian}

Instrumen penelitian merupakan alat yang dipakai dalam sebuah penelitian. Sugiyono (2016) mengatakan instrumen penelitian adalah suatu alat yang digunakan untuk mengukur fenomena alam atau sosial yang diamati. Penelitian ini menggunakan instrumen penelitian berupa kuisioner dan pedoman wawancara. Kuisioner ditujukan kepada seluruh responden sedangkan pedoman wawancara ditujukan kepada informan kunci.

\subsection{Pengujian Instrumen Penelitian}

Pengujian variabel instrumen penelitian dalam kuisioner dilakukan dengan uji validitas dan reliabilitas. Azwar (1987) dalam Matondang (2009) menyatakan bahwa validitas berasal dari kata validity yang berarti sejauhmana ketepatan dan kecermatan suatu instrumen dalam melakukan fungsi ukurnya. Sedangkan reliabilitas menurut Sugianto dan Simanjuntak (2006) dikutip dalam binus.ac.id menyatakan bahwa instrumen yang digunakan sebagai alat pengumpulan data mampu menggungkapkan informasi yang sebenarnya di lapangan. Pengujian validitas dan reliabilitas dilakukan dengan menggunakan software SPSS.

\subsection{Metode Analisis Data}

Metode analisis data yang digunakan dalam penelitian ini adalah metode analisis SWOT. Menurut BPS, analisis SWOT adalah analisis kondisi internal maupun eksternal suatu organisasi/masyarakat yang selanjutnya akan digunakan sebagai dasar untuk merancang strategi dan program kerja. Analisis internal meliputi penilaian terhadap faktor kekuatan (strength), kelemahan (weakness)dan analisis eksternal mencakup 
faktor peluang (oppourtunity)serta tantangan (threaths). Analisis SWOT ini terbagi atas analisis kualitatif dan kuantitatif.

\section{Pendekatan Kualitatif Analisis SWOT}

Pendekatan kualitatif matriks SWOT sebagaimana dikembangkan oleh Kearns menampilkan delapan kotak, yaitu dua paling atas adalah kotak faktor eksternal (peluang dan tantangan) sedangkan dua kotak sebelah kiri adalah faktor internal (kekuatan dan kelemahan). Empat kotak lainnya merupakan kotak isu-isu strategis yang timbul sebagai hasil titik pertemuan antara faktor-faktor internal dan eksternal.

\section{Pendekatan Kuantitatif Analisis SWOT}

a. Analisis IFAS dan EFAS

Data SWOT kualitatif di atas dapat dikembangkan secara kuantitatif melalui perhitungan Analisis SWOT yang dikembangkan oleh Pearce dan Robinson (1998) dalam BPS (n.d) agar diketahui secara pasti posisi organisasi yang sesungguhnya. Apabila sudah dihitung mengenai faktor IFAS dan EFAS melalui tabel diatas maka selanjutnya dapat ditentukan strategi melalui kuadran analisis SWOT dibawah ini.

b. Matriks Internal-Eksternal (IE) Analisis SWOT

Menurut Setyorini (2016) matriks ini bermanfaat untuk memposisikan analisis ke dalam matriks yang terdiri dari 9 sel. Matriks IE terdiri dari dua dimensi, yaitu total skor matriks IFE pada sumbu X dan Matriks EFE pada sumbu Y. Matriks ini dikelompokkan menjadi tiga strategi utama yaitu:

1. Grow and Build (Tumbuh dan Bina) berada dalam sel I, II atau IV. Strategi yang cocok adalah intensif (penetrasi pasar, pengembangan pasar, dan pengembangan produk) atau integrasi (integrasi ke belakang, integrasi ke depan, dan integrasi horizontal).

2. Hold and Maintain (Pertahankan dan Pelihara) mencangkup sel III, V, atau sel VII. Strategi umum yang dipakai adalah penetrasi pasar, pengembangan produk dan pengembangan pasar.

Harvest and Devest (Panen atau Divestasi) mencangkup sel VI, VIII, atau IX. Strategi yang dipakai adalah divestasi strategi diversifikasi konglomerat, dan strategi likuidasi.

\section{Hasil dan Pembahasan}

\subsection{Identifikasi Faktor Intenal dan Faktor Eksternal}

\subsubsection{Identifikasi faktor internal}

Melalui indentifikasi lingkungan internal maka dapat diketahui kekuatan dan kelemahan yang ada pada Subak Kerdung. Adapun faktor kekuatan seperti, (a) penerapan Tri Hita Karana dalam subak; (b) kemudahan mengakses modal bagi petani; dan (c) keadaan infrastruktur yang memadai. Adapun faktor kelemahan seperti, (a) pengetahuan pengurus mengetahui administrasi rendah; (b) kemampuan anggota subak dalam menerapkan teknologi dan menyerap informasi rendah; (c) pendidikan anggota subak rendah; dan (d) rendahnya minat anggota subak menjadi petani.

\subsubsection{Identifikasi faktor eksternal}

Melalui identifikasi lingkungan eksternal maka dapat diketahui peluang dan ancaman yang ada pada Subak Kerdung. Adapaun faktor peluang seperti,(a) adanya pengembangan ekowisata sebagai daya tarik wisata; (b) berkembangnya pola pikir yang menghendaki harmoni antara sektor pariwisata dengan sektor pertanian; (c) adanya 
kegiatan penyuluhan pertanian (d) adanya bantuan dari pemerintah berupa subsidi pajak PBB dan (e) adanya bantuan sarana produksi.Adapun faktor ancaman seperti, (a) alih fungsi lahan pertanian; (b) harga tanah yang tinggi (c) anak muda tidak tertarik lagi dengan pertanian; dan (d) kodisi cuaca yang tidak menentu.

\subsection{Analisis Matriks Internal-Eksternal (I-E)}

Berdasarkan pembahasan faktor kekuatan, kelemahan, peluang, dan ancaman diatas dapat ditentukan nilai IFAS dan EFAS untuk menentukan strategi pengendalian alih fungsi lahan pertanian di Subak Kerdung, Kelurahan Pedungan, Kecamatan Denpasar Selatan, Kota Denpasar. Maka dari itu dapat ditentukan posisi Subak Kerdung melaui Matriks I-E. Adapun nilai IFAS 3,09 dan EFAS 2,47. Berdasarkan gambar matriks I-E dapat dilihat pada Gambar 1 berikut.

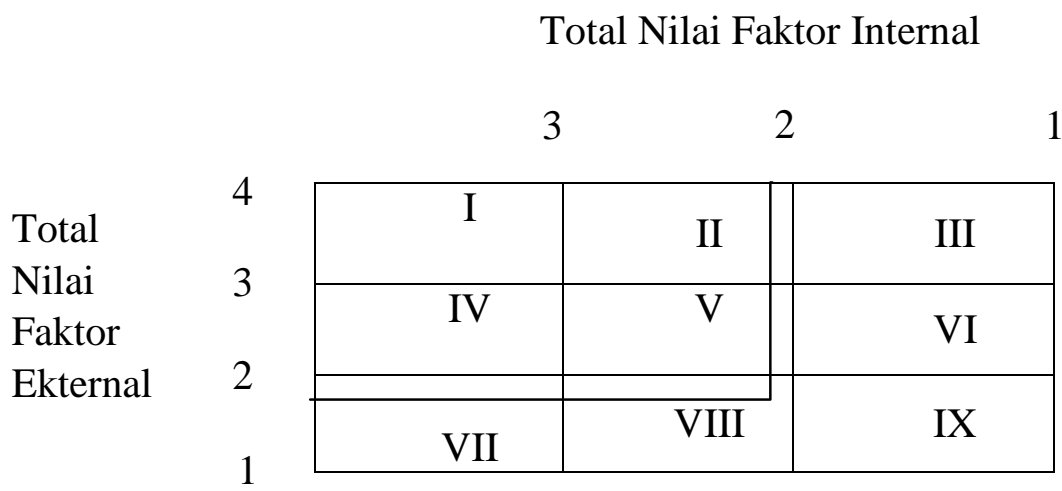

\section{Gambar 1 \\ Penghitungan Matriks Internal-Eksternal (I-E) Terhadap Subak Kerdung}

Berdasarkan gambar 1 pemetaan terhadap masing-masing total skor, baik dari faktor internal dan faktor eksternal menggambarkan posisi Subak Kerdung saat ini berada pada posisi sedang yaitu sel VII dalam matriks I-E. Strategi yang dapat dijalankan adalah strategi pertumbuhan.

\subsection{Strategi Alternatif Pengendalian Alih Fungsi Lahan Pertanian}

Berdasarkan faktor-faktor lingkungan internal dan lingkungan eksternal, maka dilakukan analisis SWOT (Strength, Weakness, Opportunities, Threats) menggunakan matriks SWOT yang disusun seperti gambar2. 


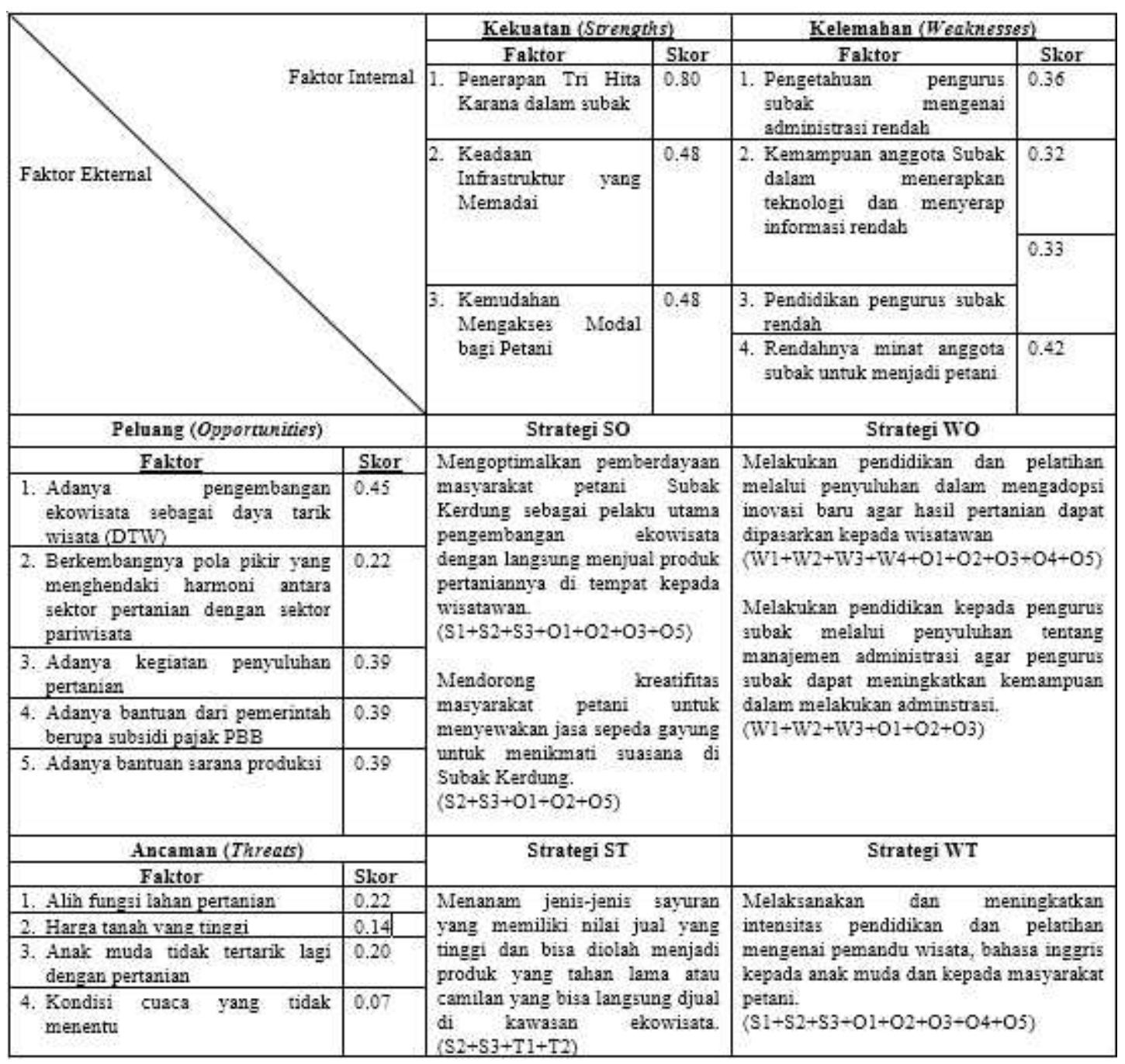

Sumber : Pengolahan Data Primer 2017

\section{Gambar 2}

\section{Penyusunan Alternatif Strategi Menggunakan Matriks SWOT}

Berdasarkan gambar 2 maka dapat dijabarkan alternatif strategi menggunakan analisis SWOT adalah sebagai berikut: (a) Strategi SO, mengoptimalkan pemberdayaan masyarakat petani Subak Kerdung sebagai pelaku utama pengembangan ekowisata dengan langsung menjual produk pertaniannya di tempat kepada wisatawan, (b) Strategi WO, melakukan pendidikan dan pelatihan melalui penyuluhan dalam mengadopsi inovasi baru serta pengolahan produk pertanian agar hasil pertanian dapat dipasarkan kepada wisatawan, (c) Strategi ST, menanam jenis-jenis sayuran yang memiliki nilai ekonomis yang tinggi yang nantinya bisa diolah menjadi suatu produk camilan dan minuman, (d) Strategi WT melaksanakan dan meningkatkan intensitas pendidikan dan pelatihan mengenai pemandu wisata, bahasa asing kepada anak muda dan masyarakat petani agar memiliki kemampuan untuk bersaing dan mengembangkan diri. 


\section{Penutup}

\subsection{Kesimpulan}

Berdasarkan hasil penelitian dan pembahasan dapat disimpulan sebagai berikut.

1. Berdasarkan hasil analisis terhadap faktor internal dan eksternal yang diidentifikasi pada Subak Kerdung dilihat dari a) Kekuatan (penerapan Tri Hita Karana dalam subak, keadaan infrastruktur yang memadai, kemudahan megakses modal bagi petani), b) Kelemahan (rendahnya minat anggota subak untuk menjadi petani, pengetahuan pengurus subak mengenai administrasi rendah, pendidikan anggota subak rendah, kemampuan anggota subak dalam menerapkan teknologi dan menyerap informasi rendah), c) Peluang (adanya pengembangan ekowisata sebagai daya tarik wisata, adanya bantuan sarana produksi, adanya kegiatan penyuluhan, adanya bantuan dari pemerintah berupa subsidi pajak PBB, berkembangnya pla pikir yang menghendaki harmoni antara sektor pertanian dengan sektor pariwisata), d) Ancaman (alih fungsi lahan pertanian, anak muda tidak tertarik lagi dengan pertanian, harga tanah yang tinggi, kondisi cuaca yang tidak menentu).

2. Berdasarkan analisis matrik SWOT diperoleh beberapa alternatif strategi diantaranya a) Strategi SO, mengoptimalkan pemberdayaan masyarakat petani Subak Kerdung sebagai pelaku utama pengembangan ekowisata dengan langsung menjual produk pertaniannya di tempat kepada wisatawan, b) Strategi WO, melakukan pendidikan dan pelatihan melalui penyuluhan dalam mengadopsi inovasi baru serta pengolahan produk pertanian agar hasil pertanian dapat dipasarkan kepada wisatawan, c) Strategi ST,menanam jenis-jenis sayuran yang memiliki nilai ekonomis yang tinggi yang nantinya bisa diolah menjadi suatu produk camilan dan minuman, dan (d) Strategi WT, melaksanakan dan meningkatkan intensitas pendidikan dan pelatihan mengenai pemandu wisata, bahasa asing kepada anak muda dan masyarakat petani agar memiliki kemampuan untuk bersaing dan mengembangkan diri.

\subsection{Saran}

Berdasarkan hasil penelitian, adapun saran yang dapat diberikan diantaranya.

1. Bagi Subak Kerdung, (a) memperbaiki kemampuan pengurus subak mengenai administrasi terutama kepemilikan lahan dengan mengikuti pelatihan, (b) penguatan Awig-awig/Parerem di subak yang membuat peraturan khusus tentang alih fungsi lahan pertanian di Subak Kerdung, menjaga dan mempertahankan kegiatan upacara keagamaan, gotong-royong yang merupakan nilai-nilai Tri Hita Karana dalam Subak Kerdung, dan (c) meningkatkan inisiatif dan partisipasi anggota subak dalam ikut serta membangun kawasan ekowisata di Subak Kerdung.

2. Bagi pemerintah, (a) diharapkan agar menerapkan pajak tanah progresif dalam memperkecil peluang alih fungsi lahan pertanian di Subak Kerdung, dan (b) meningkatkan intensitas penyuluhan terutama penyuluhan pasca panen tentang pengolahan produk pertanian menjadi produk yang memiliki nilai ekonomis yang tinggi yang bisa dijual langsung kepada wisatawan di Subak Kerdung. 


\section{Ucapan Terimakasih}

Terima kasih kepada seluruh anggota Subak Kerdung dan Pekaseh Subak Kerdung, Kelurahan Pedungan, Kecamatan Denpasar Selatan Kota Denpasar yang sudah bersedia menerima dan membantu penulis dengan menjadi responden maupun informan kunci penelitian.

\section{Daftar Pustaka}

Badan Pusat Statistik. n.d. ANALISIS SWOT dalam daps.bps.go.id/file_artikel/66/Analisis\%20SWOT.pdf diakses 22 Maret 2017.

Binus University. 2014. Uji Validitas dan Reabilitas dalam qms.binus.ac.id/u-j-i-v-a-l-id-i-t-a-a-s-d-a-n-r-e-a-b-i-l-i-t-a-s/ diakses 12 Juli2017.

BPS Bali. 2013. Kepadatan Penduduk Menurut Kabupaten/Kota di Bali dalam http://bali.bps.go.id/statictable/2018/06/28/115/kepadatan-penduduk-menurutkabupaten-kota-di-bali-2012-2017.htmldiakses 20 Juli 2018.

BPS Bali. 2013. Luas Lahan Menurut Penggunaannya di Provinsi Bali 2013. Badan Pusat Statistik Provinsi Bali.

BPS Bali. 2014. Luas Lahan Menurut Penggunaannya di Provinsi Bali 2014.BadanPusat Statistik Provinsi Bali.

BPS Bali. 2015. Luas Lahan Menurut Penggunaannya di Provinsi Bali 2015. Badan Pusat Statistik Provinsi Bali.

Matondang, Zulkifli. 2009. Validitas dan Reabilitas Suatu Instrumen Penelitian dalam http://diglib.unimed.ac.id/705/1/validitas-dan-reabilitas-suatu-instrumenpenelitian.pdf diakses 12 Juli 2017.

Setyorini, Hany. 2016. Analisis Strategi Pemasaran Menggunakan Matriks SWOT dan QSPM: Studi Kasus: Restoran WS Soekarno Hatta Malang. Department of Agroindustrial Technology, Faculty of Agricultural Technology University of Brawijaya: Malang dalam http://industria.ub.ac.id/index.php/industri/article/download/269/261 diakses tanggal 9 September 2017.

Sugiyono. 2016. Metode Penelitian Kualitatif, Kuantitatif, dan $R \& G$. Penerbit Alfabeta: Bandung.

Utomo, M, Rifai, E. Dan Thahir, A. 2014. Pengertian Alih Fungsi Lahan. (serial online), [cited 2014 oct 6]. Available from: URL: http://reponsitory.ipb.ac.id.Tesis.Fakultas Pertanian Universitas Udayana. 